\title{
REVISITING REALISTIC JOB PREVIEW FOR RECRUITMENT: A THEORETICAL PERSPECTIVE
}

\author{
Putu Chris Susanto(1) \\ Listiyani Dewi Hartika ${ }^{(2)}$ \\ (1),(2)Universitas Dhyana Pura, Bali - Indonesia \\ email: chrissusanto@undhirabali.ac.id
}

\begin{abstract}
This paper aims to revisit the theoretical concepts of Realistic Job Preview (RJP), as a human resource management approach to provide job candidates with information to better match the candidates' expectations with the realities regarding the job. Further, the paper attempts to present several considerations and strategies in implementing RJP in the socialization, selection, and retention processes of recruitment. The theoretical review presented shows that, when given properly and at the correct timing, RJP could increase job satisfaction, commitment, and performance while reducing turnover. This implies that the information shared through RJP could create a more realistic, deflated expectation about the job and the organization when presented using multiple formats.
\end{abstract}

Keywords: realistic job preview, recruitment, retention, selection, human resource

\section{ABSTRAK}

Artikel ini membahas konsep teoritis mengenai Realistic Job Preview (RJP) sebagai salah satu strategi SDM yang bertujuan menyediakan informasi realistis guna mempertemukan antara ekspektasi calon pegawai dengan kenyataan di tempat kerja. Artikel ini juga mengungkapkan beberapa pertimbangan dan strategi implementasi RJP dalam hal sosialisasi, seleksi, dan retensi dalam proses rekrutmen. Kajian teoritis dalam artikel ini mengemukakan bahwa, ketika diberikan dengan cara dan dalam waktu yang tepat, RJP dapat meningkatkan kepuasan kerja, komitmen, komitmen, dan kinerja sekaligus menurunkan angka penggantian tenaga kerja. Informasi yang didesiminasikan melalui RJP dapat menciptakan ekspektasi yang lebih realistis tentang suatu pekerjaan ketika dipresentasikan menggunakan berbagai format.

Kata kunci: realistic job preview, rekrutmen, retensi, seleksi, sumber daya manusia

\section{INTRODUCTION}

Organizations often face difficulties in recruiting, selecting, and maintaining the best qualified employees. Among the many strategies that organizations can employ to match job seekers' expectations with the reality in the job, Realistic Job Preview (RJP) can be utilized to lower job candidates' expectations and better match expectations with reality, particularly in technical jobs (Cunningham, 2015). The primary goal of RJP is to reduce unnecessary costs incurred by hiring ill-informed candidates who voluntarily leave the organization when the reality of the job is not as they expected (Graef et al., 2002). This goal is directly related to lower turnover and indirectly related to increased job satisfaction and improved performance (Pane Haden, 2012; Wanous, 1980).

In essence, RJP is a recruiting tool that organizations employ to communicate the desirable and undesirable aspects of a job to prospective employees before they start working for the organization, which helps candidates acquire a more accurate picture, and thus expectations, on the job and the hiring organization (Cunningham, 2015).

RJP helps job candidates in their decisionmaking process, particularly in the information search and alternative evaluation stages, because many candidates often have unrealistically inflated expectations about the organization they consider joining. By providing realistic information about the job and organizational culture, employers also benefit from filtering out ill-fitted candidates. RJP lowers candidates' expectations to a more realistic level (Cunningham, 2015). RJP also provides a reference on what employees could expect from the employer and vice versa. RJP is expected to ease the organizational socialization process, improve role perception, overall job satisfaction and performance (Cunningham, 2015; Pane Haden, 2012).

The purpose of this paper is to revisit the underpinnings of RJP as a recruitment tool from a theoretical perspective then to give some general strategies to implement RJP. As such, this paper attempts to discuss the functions of RJP in the dual- 
matching process between candidates' expectations and organization's needs, the roles of RJP in "vigilant information processing" (VIP) for job candidates, as well as the benefits of RJP in organizational socialization and reducing turnover, before suggesting some considerations and approaches for the implementation RJP in organizations. The paper is descriptive in nature, using secondary research method to present a synthesis of classical and contemporary literatures and conceptual frameworks on RJP categorically. Secondary research refers to a research strategy that reviews, summarizes, and synthesizes existing or published research in order to make sense of a phenomenon (Crouch and Housden, 2003: 23). The secondary research method employed is theoretical review, describing and analyzing the development of RJP theories, drawing from existing research and published findings.

\section{DISCUSSION}

The term RJP was first introduced by Wanous (1977), who further suggested that RJP does not refer to any specific technique, but rather a general approach to ease entry and socialization of new hires that would positively affect job performance and commitment. Wanous (1980) elaborated that organizational entry involves a dual matching process between (1) the candidate's qualifications and the job requirements, and (2) the candidate's needs and the organizational culture. The first match has the greatest impact on performance, while the second match has a negative correlation with turnover. A mismatch of the individual's needs and the nature of work or organization could lead to decreased job satisfaction and decrease in commitment. Initially, RJP began as an alternative to the "seduction" method of recruiting, i.e., only telling candidates positive information regarding the job (Baur et al., 2014). After organizational entry, there could be a period when initial expectations are unconfirmed, which usually leads to dissatisfaction (Popovich and Wanous, 1982).

For the individuals, as candidates then as new hires, RJP has an impact on individual decisionmaking and early socialization to the organization. Searching for an employment is a major decision, involving sequential and logical decision-making processes. RJP aids candidates in their "vigilant information processing" (VIP) for decision-making, which refers to a step-by-step process in decisionmaking resulting in effective decisions (Rai, 2016; Janis and Mann, 1977). VIP is regarded as a coping mechanism to counter the internal conflicts and stress that may arise in an individual decision-making process, including in the decision-making process for employment. Rai (2016) suggested that stress experienced in decision-making process affects individual behavior and that stress tends to increase as the risks involved in a particular decision increase. As choosing the right employment is a major decision for many individuals, high risks and thus stress may be present. As such, individuals should be more vigilant.

\section{RJP in Dual-Matching Process}

The dual matching process is an attempt to match candidates' qualifications and needs, with the organization's needs and the job being offered. Porter, et.al. (1975) suggested that this process involves mutual attraction between the candidate and the organization. The process also functions to select candidates whose values are compatible with organization's (Chatman, 1991).

However, conflicts may occur during the attraction and selection process. One of which occurs because the organization does not give complete or accurate information about the job. Recruiters, who are used to "selling" the organization and the position, often give biased job descriptions and only positive information (Wanous, 1980). This could lead to overly inflated individual's expectation of the job for which he is applying. RJP helps mitigate this particular conflict in organizational selection (Wanous, 1980). It has positive effects for both the individual and the organization.

Often, the recruitment experience is the first direct contact that job candidates have with the potential employers. This is especially true in an age when job search has become synonymous with internet search (Cunningham, 2015). Because candidates have limited information about the company, especially for entry-level candidates with no previous work experience, many rely heavily on information posted online and the recruitment process to gain understanding about the organization and its work culture.

RJP could also be effective in screening out illfitted candidates and those who are likely to stay employed for a very short period. Masternak (2004) cited an experiment done in Wayne State University in 1996 that indicates that $36.1 \%$ of job candidates in the RJP group declined a job offer compared to the control group at 9.2\%. Masternak (2004) also gave an illustration that PETsMART, a pet supply chain, was able to screen out $15 \%$ of the candidates' 
job candidates just by showing a 10 -minute RJP video. RJP was important to inform candidates what it takes to work in a pet store. The candidates screened out were more likely to leave the company in the first three months.

There are two other benefits of RJPs: accuracy of expected job information and perceived climate of honesty (Baur etal., 2014, Phillips, 1998). When it comes to honesty, realistic but not overwhelmingly negative information, may enhance candidates' perception on the trustworthiness of the organization (Baur et al, 2014; Thorsteinson et al., 2004). The University of Idaho study found that higher quality candidates were not affected differentially by the favorability of the message, while realistic information on certain characteristics of the job was found to increase the attractiveness of the company and encourage self-selection for ill-fitted candidates (Thorsteinson et al., 2004).

\section{RJP in Vigilant Information Processing for Job Candidates}

Traditionally recruiters have to select individuals that would be a good match, as well as to "sell" the organization to the general public during the recruitment process. The organizational selling technique often involves exclusively communicating overtly positive characteristics of the job rather. Overemphasizing the positive and omitting the negative characteristics about an organization may create a bias during the recruitment process, which could increase the difficulties for new hires to integrate into the organization, which could lower job satisfaction and increase turnover (Baur et al., 2014). This bias often prevents the candidate to fully employ vigilant information processing (VIP) in the career decision-making process.

Vigilant information processing (VIP) is a series of seven criteria necessary for making high quality decision making. Developed by Janis and Mann (1977), the sequential VIP process include: (1) Thoroughly examining a wide range of alternative courses of action; (2) Surveying the full range of objectives and the values implicated by the choice; (3) Carefully weighing the costs and risks of negative and positive consequences of each alternative; (4) Intensively searching for new information relevant to further evaluation of the alternatives; (5) Taking into account of any new information or expert judgment, even when the information or judgment does not support the currently preferred course of action; (6) Reexamining the positive and negative consequences of all known alternatives; (7) Making provisions for imple-menting the chosen course of action.

RJP comes in the fifth and sixth steps of VIP, which helps the candidate assess the individualorganizational fit. RJP serves as an expert information because it comes from within the organization with the goal to help the job seekers better decide whether they fit with the organization. The job seekers must go back to their balance sheets and reevaluate the values given to each potential job offer before making a final choice. In order for the RJP to be effective, candidates must be able to turn down the job that, based on the RJP, does not meeting her needs and expectations (Breaugh, 1983).

Decisions made without VIP may temporarily reduce stress because the quick decision was made without thoroughly weighing all foreseen factors. However, not thoroughly considering all the implications and alternatives of a major decision may result in post-decisional remorse, long-term dissatisfaction, and bolstering. According to Janis and Mann (1977), bolstering refers to a psychological technique that a decision maker uses to maintain or even exaggerate the image of a successful outcome out of the poorly made decision.

For potential employees, RJP allows for selfselection. With RJP, candidates have the opportunity to determine if there is a match between their needs and the job requirements. Bourgeois (2003) argued that for the candidates that pass the selection process, RJPs positively affect retention because candidates are given realistic information before joining the organization. Thus, in the recruitment process RJP discourages ill-fitted employees to pursue the process further, which could save the company training and turnover.

\section{RJP in Organizational Socialization}

Organizational socialization is a process in which a new hire learns the organizational values, norms and required behaviors (Riley, 2002). Porter et al. (1975) divided the socialization process into three distinct stages that are most familiar in the field of organizational behavior today: pre-arrival, encounter, and metamorphosis. As socialization relates to RJP, Wanous (1980) suggested a comprehensive model of new employee socialization, which has four stages: (1) Confronting and accepting organizational reality; (2) Achieving role clarity; (3) Locating oneself in organizational context; (4) Detecting signposts of successful socialization.

RJP has most prominent effects in the first two stages of the four-stage model described above. 
Upon accepting the job offer, new hires develop expectations about the organization. The goal of RJP is to bring the initial expectations to a realistic level (Cunningham, 2015). Once joining the organization, expectations are either confirmed or disconfirmed. RJP is valuable because employee satisfaction increases as more of the expectations are confirmed (Breaugh, 1983).

RJP also enables new employees to better understand their roles within the organization, with respect to peers and supervisors. At this stage, new employees learn to cope with resistance to change and to work with the given degree of structure or ambiguity (Wanous, 1980). Breaugh suggested that the coping mechanism is strengthened because they employees have been forewarned about potential workplace issues and conflicts (1983). Masternak (2002) added that RJP makes new employees aware of the potential problems to be faced on the job, and would be less likely to leave in the early stages of employment.

For new hires, RJP brings their initial expectations to a more realistic level. The lower the expectation, the easier it is to fulfill. The more expectations are met, the greater the satisfaction (Riley, 2002). The opposite is also true. Deflated and thus more realistic initial job expectation could potentially increase overall satisfaction. Wanous (1989) cited a meta-analysis of 21 experiments, which indicated that RJP lowers expectations ( $r=-$ 0.17). This means that RJP has a weak negative correlation with new employee expectations. As such, RJP has the potential to better prepare the new employees for reality.

Another potentially long-term impact of RJP is organizational commitment. This is a concept that governs individual's identification with the organization and extent to which an individual buys in to organizational goals and values. Organizational commitment is also a matching process between individual needs and organizational climate, resulting in both commitment and job satisfaction (Riley, 2002).

Overall, RJP prepares new hires for organizational entry, in which the individuals gain considerable knowledge about the job and the organization. RJP improves the attitude of new employees by providing accurate information for the job choices that they make (Popovich and Wanous, 1982). In turn, this would ease the organizational socialization process, while increasing satisfaction and commitment to the organization.

\section{RJP in Reducing Turnover}

One of RJP's effects is its correlation to employee survival and turnover rates. This is true because turnover is a measurable, concrete behavior which has a big impact on the employer's bottom line (Popovich and Wanous, 1982). Although not all turnovers are bad, most turnover are costly. Bourgeois (1999) illustrated this impact by citing that for a hotel with thirty employees and a 50\% turnover rate, turnover costs reaches $\$ 150,000$ per year.

The findings on the effects of RJP on turnover have been mixed. Wanous (1980) stressed that RJP is aimed at reducing voluntary, not involuntary, turnover. In a meta-analysis study, Phillips (1998) examined 40 research studies and found the mean correlation for the effects of RJPs on voluntary turnover $=-0.09$, which means that RJP only has a very weak negative correlation to voluntary turnover. However, when the findings were put into context, an organization experiencing an annual job survival rate of 50 percent when recruiting with traditional methods could make 17 fewer hires per year per 100 retained workers by implementing RJP (Phillips, 1998). Further, the adoption of RJPs could be expected to save the organization US $\$ 71,111$ in voluntary turnover costs per 100 retained workers (Phillips, 1998). Wanous (1980) compared the survival rate of RJP group to the control group in from 13 different experiments and found that RJP resulted in an average gain in job survival of 12 percent.

The impact of RJP in new employee performance, however, is not thoroughly confirmed by research studies. A meta-analysis by Phillips (1998) found that videotaped RJP only had a weak correlation with higher job performance $(r=0.18)$ and that written RJPs were found to unrelated to job performance. However, studies on the correlation between RJP and performance have not been as prominent as the turnover studies. Pane Haden (2012) found that RJP does not consistently lead to higher performance, which partly can be attributed to poor goal setting. However, as performance has an indirect effect on turnover, some of RJP's impact on turnover can be traced back to actual performance.

\section{RJP IMPLEMENTATION}

The information presented in RJP allows the job candidates to make an educated decision about their job choice (Riley, 2002). O'Nell (2001) stressed the importance of RJP in "hidden" industries, such as human service, where many potential employees may not have any information about the tasks and 
responsibilities of the job. Breaugh (1983) asserted that when it comes to the type of job, RJP is most appropriate for entry-level positions, because candidates seeking entry-level positions are usually fresh to the job market. They are more likely to have unrealistic expectations due to limited information (Breaugh, 1983). Reilly et al. found the effects of RJPs on turnover to be more than four times as great for complex jobs compared to entrylevel positions.

As for RJP implementation, recruiters must consider the following: (1) When should RJP be given to candidates?; (2) For which job types RJP is most suitable? Should it be general or jobspecific?; (3) Which medium would be most appropriate for RJP?; (4) What is the appropriate content for the message? How much negativity should be included?

\section{Timing of RJP}

The real dilemma is whether to give the RJP early in the application process, in the middle of recruitment, or after the job offer is accepted. Wanous (1989) suggested that using RJP in the early stage of the recruitment process could be more effective because candidates become more invested in the job as they move along in the recruitment process. Recruiters should consider that the longer they wait to do any type of RJP, the greater the risk that the candidates will develop "deaf ears" because would still take the position in spite of new information presented.

Researchers have proposed that realistic information administered after job offer acceptance serves a different purpose compared to RJP because the opportunity for job candidates to self-select out of the application process no longer exists. There is a virtue and risk to delivering RJP early. By having an early RJP, the organization allows candidates to make a more informed choice whether to continue on with the recruitment process (Griffeth and Hom, 2001). However, if too much information is communicated too early, RJP could lead to adverse self-selection on qualified candidates.

The solution could be RJPs in different stages throughout the recruitment process. For example, one RJP session can be conducted after candidates pass the initial test. This could primarily inform the candidates about the organization. Then, a more indepth and job-specific RJP is presented once one or two interview sessions have taken place. This will greatly help candidates in the VIP process, by either allowing self-selection or decreasing inflated expectations about the job. After the job offer has been extended, but before the new employee starts working, a current job incumbent could present a subjective RJP to ease the early socialization process.

\section{Extent of RJP}

The first dilemma of RJP timing correlates with the next, which is the extent of information included in RJP: whether it should be all encompassing for the entire organization or specific to the job types. Wanous (1989) suggested that if a broad RJP message is used, candidates are likely to miss important information. RJP could focus on general organizational information when presented early and on detailed and job-specific information when presented later. More detailed, realistic socialization could then provide the most task-oriented information of all, focusing on performance expectations for all employees and coping strategies to handle stressful work situations.

\section{Medium of RJP}

RJP can be implemented in various ways, including brochures, audiovisual media, live presentation, and work sample. Brochure is cost effective and easy to update, but there is no guarantee that job candidate would read it (Wanous, 1989). Audio-visuals are more expensive, but offer more vivid description of the organization (Riley, 2002). Viewing the tape can be a mandatory activity for new hires or candidates who pass the preliminary test. Videotapes allow recruiters to present situational illustration, such as conflict resolution and frustration in the workplace (Griffeth and Hom, 2001).

Another RJP medium is subjective reality-the job situation as seen through job incumbents (Wanous, 1989). This is a more interactive, much more subjective way of presenting RJP to new recruits. However, as opposed to asking veteran incumbents to present the RJP, I believe that it would be more effective to also have a relatively new member of the company to present the realities of the job, especially since the recruiting process would still be fresh in the newer employees' minds.

\section{Content of RJP Message}

It is essential that RJP, in any form, could be identify unrealistic expectations that job candidates may have and address these concerns with a realistic view of the job and company's culture. It is also important that the recruiters are open about the 
purpose of RJP. Wanous (1980) suggested that recruiters could explicitly encourage self-selection. By telling the candidate to consider the RJP information carefully and to make a thoughtful decision about accepting an employment offer, the organization presents itself as being caring and trustworthy as well as encouraging the candidate to make an effective job choice (Masternak, 2004). While RJP content varies between organizations and job types, it could keep an overall focus on factors that are most important, directly correlated with turnover, and most misperceived by recruits (Wanous, 1989).

The content could be descriptive, judgmental, or a combination of both approaches. While descriptive materials are much easier to defend, Wanous (1989) suggested RJP could incorporate judgmental content. Judgmental content not only describes about the work experience, but also demonstrates how a typical employee think, feel, and behave under certain work situation. However, recruiters need to take caution when developing the message to minimize the risk of RJP being seen as biased.

The degree of negativity to be disclosed on RJP is on a continuum, from low to high degree. A high degree of negative information enhances selfselection among job candidates, but it may discourage potential employees to apply for the job and it could show management's negligence (Wanous, 1989). Recruiters could develop RJP content with medium degree of negativity, which allows moderate self-selection while encourages new employ coping strategies at the same time.

\section{CONCLUSION AND RECOMMENDATIONS}

RJP is an organizational approach to the inflated, unrealistic expectations that many job candidates may initially have, especially candidates who are not unfamiliar the company or industry. During the dual matching process, in which the individual and the employer attempts to attract each other while reduce uncertainty, RJP is beneficial as a vigilant information processing tool for the candidate and as an adverse self-selection mechanism that could save money for the employers. The most measurable outcome of this program is reduced employee turnover. While not all turnovers are bad, most are costly. Wanous (1980) noted that the purpose of RJP is to decrease voluntary, not involuntary, turnover. RJP also eases the socialization process of new hires, which positively affect job performance and commitment with the organization.

RJP implementation is not considered successful if it was not "realistic" enough. Griffeth and Hom (2001) claimed that in order for RJP statements to be considered "realistic," they have to be seen as true by at least $70 \%$ of job incumbents. Regardless, RJP must clarify its purpose, provide credible information, include information about how job incumbents feel about their jobs, and incorporate both positive and negative experience about the job (Larson, O'Nell, and Sauer, 2005).

When recruitment budget allows, recruiters should develop a multi-stage RJP program, using printed brochure, videotaped situations, and live presentation by a job incumbent. Different media can be used at different points of recruitment. For example, upon initial test or first interview, job candidates could be presented with the brochure. Candidates seeking information to make a better job decision would want to review this handout. However, there is no guarantee.

As the interview process rolls along, recruiters could require candidates to watch an RJP video (enacted by actors or actual employees) as they enter a certain round of interview. Lastly, before the new hires start working (preferably after the job offer has been made but before it is accepted), candidates can sit down on an RJP presentation by current employees. A team of veteran incumbents and relatively new employees makes the best presenters. The new hires will gain perspective about the longevity and commitment for the job, as well as a fresh take on organizational entry and coping mechanism. Overall, recruiters could make it clear that the purpose of RJP is to lower expectation, to increase job satisfaction, and to decrease new employee turnover. The content could be more job-specific and could incorporate mediumlevels of negativity to increase perceived credibility of the organization.

At the end, when an organization is considers implementing RJP as a part of its recruiting, it must take into account the timing, scope, message, and medium of the program. A multimedia, multi-stage approach in which the organization uses brochures, video, and live presentation of a more job-specific RJP with medium negativity content at different stages of the hiring process is recommended. RJP could not be introduced too early, nor too late in the recruitment process because that may decrease its effectiveness. 


\section{REFERENCES}

Baur, J.E., Buckley, M.R., Bagdasarov, Z., and Dharmasiri, A.S. 2014. A historical approach to realistic job previews. Journal of Management History, 20(2): 200-223.

Bourgeois, N. 1999. Factors influencing the effects of realistic job preview on candidate judgments of organizational attractiveness. Thesis, Louisiana State University.

Breaugh, J.A. 1983. Realistic job preview: A critical appraisal and future research directions. The Academy of Management Review, 8(4): 612619.

Chatman, J.A. 1991. Matching people and organizations: Selection and socialization in public accounting firms. Administrative Science Quarterly, 36: 459-484.

Crouch, S. and Housden, M. 2003. Marketing research for managers. Chartered Institute of Marketing. Oxford, UK: Butterworth-Heinemann.

Cunningham, C. 2015. Interactive realistic job preview: Managing candidate expectations and engaging future applicants. [pdf] Farmington Hills, MI: Logi-Serve. Available at: $\log i-$ serve.com/documents/Logi_Serve_Value_ of_RJP_2015_11_18.pdf. [Accessed 16 Jun. 2016].

Graef, M.I., Potter, M.E., and Rohde T.L. 2002. Continuing innovations in CPS staff recruitment and selection: Results of a statewide test validation study. University of Nebraska-Lincoln.

Griffeth, R. W. and Hom, P.W. 2001. Retaining valued employees. Thousand Oaks, CA: Sage.

Janis, I.L. and Mann, L. 1977. Decision making: a psychological analysis of conflict, choice, and commitment. New York, NY: Free Press.

Larson, S.A, O'Nell, S.N., and Sauer, J.K. 2005. What is this job all about? Larson, S.A. andHewitt, A.S. (Eds). Staff Recruitment, Retention, and Training Strategies. Baltimore, MD: Brookes, 47-74.

Masternak, M. (2004). Realistic job preview: A review of the literature and recommendations for Michigan family independence agency, [pdf] Michigan: CPS Human Services. Available at: http://www.cps.ca.gov/ConsultingServices/ HSR C/MIFI AAppendices/Append G_FIA_CCHP_Realistic_Job_Preview.pdf. [Accessed 16 Jun. 2016].

O’Nell, S. et. al. 2001. RJP overview. Minneapolis: University of Minnesota Institute on Community Integration.

Pane Haden, S.S. 2012. Realistic job previews and performance: The mediating influence of personal goals. Journal of Management Research, 12(3): 163-178.

Phillips, J.M. 1998. Effects of realistic job previews on multiple organizational outcomes: A metaanalysis. The Academy of Management Journal, 41(6): 673-690.

Popovich, P., and Wanous, J. P. 1982. The realistic job preview as a persuasive communication. Academy of Management Review, 7: 570-578.

Porter, L.W., Lawler, E.E. III, and Hackman, J.R. 1975. Behavior in organizations. New York: McGraw-Hill.

Rai, S. 2016. The relationship between self efficacy and decision making on academic performance of adolescents. International Journal for Technological Research In Engineering, 16, 133-136.

Riley, S. 2002. Network ties as a predictor of realistic job previews. Thesis. Central Connecticut State University.

Thorsteinson, et. al. 2004. Too good to be true? Using realism to enhance candidate attraction. Journal of Business and Psychology, 19(1): 125-173.

Wanous, J. P. 1977. Organizational entry: Newcomers moving from outside to inside. Psychological Bulletin, 84: 601-618.

Wanous, J.P. 1980. Organizational entry: Recruitment, selection, and socialization of newcomers. Reading, MA: Addison-Wesley.

Wanous, J. P. 1989. Installing a realistic job preview: Ten tough choices. Personnel Psychology, 42: 117-134. 